\title{
Risk of COVID-19 Transmission During Gastrointestinal Endoscopy
}

\author{
Surinder Singh Rana ${ }^{1}$ \\ ${ }^{1}$ Department of Gastroenterology, Post Graduate Institute of \\ Medical Education and Research (PGIMER), Chandigarh, India
}

\begin{abstract}
Address for correspondence Surinder Singh Rana, MD, DM, FASGE, Department of Gastroenterology, PGIMER, Chandigarh 160 012, India (e-mail: drsurinderrana@gmail.com).
\end{abstract}

J Digest Endosc 2020;11:27-30
Abstract
Keywords
- endoscopy
- coronavirus
- air droplets
- fomites
- pneumonia

COVID-19 is a viral illness caused by a novel severe acute respiratory syndrome Coronavirus 2 (SARS-CoV-2). It is highly contagious virus with human-to-human transmission being primarily attributed to direct contact or air droplets. It is highly infectious and contagious due to high-viable viral loads in the upper respiratory tract secretions of infected patients and also similar viral load being detected in both asymptomatic and symptomatic patients. The virus stability characteristics and modes of transmission via fomites and air droplets make gastrointestinal ( $\mathrm{Gl}$ ) endoscopy a highrisk procedure for COVID-19 transmission. This review discusses the currently available literature on risk of transmission of SARS-CoV-2 during Gl endoscopy.

\section{Introduction}

In December 2019, Wuhan city of Hubei province, China, reported a cluster outbreak of viral pneumonia that was subsequently confirmed to be caused by a new coronavirus named severe acute respiratory syndrome coronavirus 2 (SARS-CoV-2), and the disease caused by it was termed as Coronavirus disease 2019 (COVID-19) by World Health Organization (WHO) ${ }^{1,2}$ Coronaviruses are a group of related medium-sized viruses that are enveloped, positive-sense, single-strand RNA viruses which cause respiratory illnesses in the humans. ${ }^{3,4}$ The name Coronavirus is derived from the crown or halo-like appearance of virion on electron microscopy. This appearance is due to large bulbous projections of envelope glycoproteins on its surface. ${ }^{5}$ The human respiratory disease is usually caused by six species of Coronavirus, and a majority of them cause self-limiting mild respiratory illness. However, occasionally, they can cause fatal pneumonia, as was seen in 2002 with severe acute respiratory syndrome coronavirus (SARS-CoV), and in 2012 with Middle East Respiratory Syndrome (MERS) coronavirus. ${ }^{1,4}$ The novel SARS-CoV-2 is also a highly infectious and contagious virus that has potential to cause severe and fatal disease in humans.
The most common symptoms of COVID-19 are fever, fatiguability and respiratory tract symptoms such as cough and shortness of breath. Gastrointestinal (GI) symptoms, mainly diarrhea and vomiting, have also been reported in some studies.,6-8 Minority of patients with COVID-19 develop acute respiratory distress syndrome (ARDS), and fatality rate of up to $3.5 \%$ has been reported consequent to septic shock, refractory metabolic acidosis, and coagulation dysfunction., ${ }^{2,6-8}$ Older people and patients with underlying comorbidities like cardiovascular disease, diabetes, chronic lung diseases, and malignancies are more likely to develop serious illness as well as fatality. ${ }^{1}$ Currently, there is neither an effective treatment nor a vaccine for prevention of infection with SARS-CoV-2, although there are many ongoing clinical trials with potential drugs. The only effective preventive measure currently is effective infection control, personal hygiene, and isolation.

\section{Modes of Transmission of SARS-CoV-2}

Initial studies indicated that SARS-CoV-2 occurred because of animal-to-human transmission, as the authors found linkage between wild animal market and its occurrence. ${ }^{9}$ However, subsequently, human-to-human transmission 
was also confirmed. ${ }^{1}$ Human-to-human transmission has been primarily attributed to direct contact or air droplets. ${ }^{4,6,8}$ Respiratory tract infections can be transmitted through air droplets of varying sizes. The droplet particles $>5$ to $10 \mu \mathrm{m}$ in diameter are termed as respiratory droplets and droplets $<5 \mu \mathrm{m}$ in diameter are termed as droplet nuclei. ${ }^{1}$ The currently available evidence suggests that SARS-CoV-2 is primarily transmitted between people through respiratory droplets and contact routes. ${ }^{1,4,6,8-11}$ It is important to understand the difference between respiratory droplets and droplet nuclei. The airborne transmission suggests transmission of infection by infected droplet nuclei. As mentioned above, droplet nuclei are $<5 \mu \mathrm{m}$ in diameter and can remain in the air for long periods of time and also transmitted over distances $>1 \mathrm{~m} .{ }^{1}$ The size of the exhaled aerosol depends upon many factors including the characteristics of the fluid, force and pressure at the moment of emission of aerosol, and surrounding environmental conditions like temperature, humidity and air flow. The particles of large size remain in air for a brief period and usually settle within $1 \mathrm{~m}$ from the emitting source, whereas droplet nuclei remain suspended in air for longer periods of time. ${ }^{1}$

The droplet transmission of viral illnesses usually occurs when a person is in in close contact (usually within $1 \mathrm{~m}$ ) with someone who has active viral shedding in respiratory secretions, and activities like coughing or sneezing generate infective air droplets. These infective air droplets can infect surrounding person through his/her exposed mucosae (mouth and nose) or conjunctiva (eyes). ${ }^{1}$ The transmission can also occur through infected fomites like stethoscope, thermometer, or endoscope. The viability period of SARS-CoV-2 on fomites is variable with a study demonstrating it to be detectable for 72 hours on plastic and stainless steel, but the viability period being less on copper and cardboard surfaces. ${ }^{12}$

The worrying aspect of COVID-19 transmission is that in certain clinical situation airborne transmission may also be possible. The airborne transmission may be possible during procedures that generate aerosols like nebulization, endotracheal intubation, bronchoscopy, open suctioning, manual ventilation before intubation, disconnecting patient from the ventilator, noninvasive positive-pressure ventilation, tracheostomy, and cardiopulmonary resuscitation. ${ }^{1,13}$ A study using a three-jet Collison nebulizer and fed into a Goldberg drum to create an aerosolized environment demonstrated that the SARS-CoV-2 virus remains viable in aerosols for a period of up to 3 hours (duration of the experiment). ${ }^{12}$ There are also reports of detection of viral RNA in various environmental samples both for SARS-CoV-1 as well as SARS-CoV-2. ${ }^{12,14}$ van Doremalen et al demonstrated that the stability of SARSCoV-2 was similar to that of SARS-CoV-1. ${ }^{12}$ Although concerning, detection of viral RNA in environmental samples is not indicative of viable transmissible virus, and further studies are required to find out whether viable SARS-CoV-2 virus is present in air samples from room with COVID-19 patients, where no aerosol-generating procedures are being conducted.

Although having similar stability to SARS-CoV-1, COVID-19 is more infectious and contagious. This difference is possibly due to high-viable viral loads in the upper respiratory tract (nose more than the throat) and also similar viral load being detected in both asymptomatic and symptomatic patients. ${ }^{15,16}$ This potential of SARS-CoV-2 to shed and transmit even in asymptomatic patient is one of the key factors responsible for its rapid spread across the continents. ${ }^{1,16}$ There are also reports of fecal shedding of COVID-19 virus, both in symptomatic and asymptomatic patients, and this raises concern of a fecal-oral route of transmission. ${ }^{7,17}$ Despite this, there have been no reports of fecal-oral transmission of SARS-CoV-2 to date. ${ }^{1,4,6}$ Salivary glands being a potential reservoir for SARS-CoV-2 is also a matter of concern. ${ }^{18}$ There is also report of aircraft transmission of COVID-19, raising concerns of its transmission in closed spaces. ${ }^{19}$

\section{Risk of SARS-CoV-2 Transmission During Endoscopy}

Currently, there is no report of SARS-CoV-1 or SARS-CoV-2 transmission through endoscopy. However, the virus stability characteristics and modes of transmission, as described above, make GI endoscopy a high-risk procedure for COVID-19 transmission. The possible ways COVID-19 transmission can occur in an endoscopy suite include person-to-person via direct contact, as endoscopy involves close contact with the patients or respiratory droplets, generation of infected aerosols during endoscopy, and through contact with contaminated endoscopic equipment, accessories and body fluids. ${ }^{20}$ It is important to understand that both upper and lower GI endoscopy procedures carry the risk of transmission of COVID-19.

\section{Why Staff in Endoscopy Units are at High-Risk of Acquiring COVID-19?}

There are many factors that put the staff in endoscopy unit at high-risk of acquiring COVID-19 infection. First, endoscopy suites are relatively small and closed units with several people including endoscopists, nursing staff, technicians, anesthetists, hospital attendants, patients waiting for multiple procedures, and large number of small and big equipment. Both these factors are part of an ideal recipe for person-to-person as well as fomite transmission of SARS-CoV-2. Theoretically, a patient with high-viral load in the respiratory secretions can contaminate the endoscopy suite's air as well as fomites with virus that can remain viable for a longer duration, thus putting uninfected patients as well as endoscopy staff at risk. Second, a variety of endoscopic procedures including gastroscopy, colonoscopy and endoscopic retrograde cholangio-pancreatography are performed every day, wherein the endoscopists access the GI lumen from a close distance and therefore get exposed to a large number of respiratory, oropharyngeal and gastrointestinal flora. ${ }^{21,22}$ Also, many of these procedures are of significantly longer duration, and this further increases the risk of infection to the endoscopist. Johnston et al reported a significant unrecognized exposure to the endoscopist's face of potentially infectious biologic samples during endoscopy. ${ }^{23}$ Also, unrecognized contamination was observed on the walls of endoscopy suites. Moreover, fecal shedding of SARS-CoV-2, 
especially in asymptomatic patients, opens an altogether new dimension in its transmission. Although, currently there are no reports of feco-oral transmission of COVID-19, viral fecal shedding is a matter of concern because viable virion in the stool could increase the risk of transmission to endoscopy staff during colonoscopy.

Third, gastrointestinal endoscopy is a procedure than can generate aerosols. Although there are no studies that have systematically looked at the type and frequency of aerosol generation during endoscopy, endoscopy should be considered as an aerosol-generating procedure. ${ }^{20,24}$ It is known that coughing and retching can occur during upper endoscopy and this is known to generate aerosols. Similarly, while doing colonoscopy, passage of flatus may disseminate infective microorganisms into the surroundings. ${ }^{25}$ Moreover, routine maneuvers done while performing endoscopy, including suctioning and multiple exchanges of catheters/accessories, increases the risk of splashing and spread of infective material to the endoscopy staff. ${ }^{20}$ Fourth, SARS-CoV-2 virus has been detected in the gastric, duodenal and rectal biopsies, and this is also a potential source of infection in an endoscopy setting. ${ }^{17}$

As SARS-CoV-2 can be transmitted via fomites also, there is a risk of transmission of virus to uninfected patients via contaminated endoscopes, as happened previously with hepatitis $\mathrm{B}$ and $\mathrm{C}$ and various multidrug resistant organisms. However, it appears that current disinfection and reprocessing guidelines as advocated by American Society for Gastrointestinal Endoscopy and European Society of Gastrointestinal Endoscopy are sufficient to disinfect the endoscopes from SARS-CoV-2 also. 24,26,27

\section{Conclusion}

The virus stability characteristics and modes of transmission of SARS-CoV-2 make GI endoscopy a high-risk procedure for COVID-19 transmission There is an explosion of knowledge on various transmission kinetics of COVID-19, and several guidelines and recommendations for its prevention in endoscopy suites have been advocated. However, the screening protocols prior to endoscopy include the considerable challenges of identifying asymptomatic, minimally symptomatic patients shedding virus in their secretions, or patients shedding virus even after the resolution of symptoms. Despite these concerns, the results of recent study from Italy have demonstrated that the risk for both patients and health care workers to acquire clinically relevant COVID-19 infection during endoscopy appears to be low. ${ }^{28}$ The authors speculated that this low risk suggests that as relatively simple measures, such as use of double-surgical masks could prevent infection in endoscopy, airborne droplets rather than aerosol seem to be the dominant route of COVID-19 infection. They also felt that these results suggests that orofaecal transmission during colonoscopy is unlikely. These results are reassuring but more studies with robust design are needed to ascertain the exact risk of COVID-19 transmission during GI endoscopy.

\section{Conflict of Interest}

There are no conflicts of interest or financial disclosures to be made.

\section{References}

1 WHO. Pneumonia of unknown cause - China. Available at: http://www.who.int/csr/don/05-january-2020-pneumoniaof-unkown-cause-china/en/. Accessed April 14, 2020

2 Zhu N, Zhang D, Wang W, et al; China Novel Coronavirus Investigating and Research Team. A novel Coronavirus from patients with pneumonia in China, 2019. N Engl J Med 2020;382(8):727-733

3 Virology: Coronaviruses. Nature 1968;220:650

4 Repici A, Maselli R, Colombo M, et al. Coronavirus (COVID-19) outbreak: what the department of endoscopy should know. Gastrointest Endosc 2020;(e-pub ahead of print). doi /j.gie.2020.03.019

5 Tyrrell DAJ, Myint SH. Coronaviruses. In: Baron S, ed. Medical Microbiology. 4th ed. Galveston (TX): University of Texas Medical Branch at Galveston; 1996 Available atAccessed April 14,2020

6 Chatterjee P, Nagi N, Agarwal A, et al. The 2019 novel coronavirus disease (COVID-19) pandemic: a review of the current evidence. Indian J Med Res 2020;(e-pub ahead of print). doi ijmr.IJMR_519_20

7 Li LY, Wu W, Chen S, et al. Digestive system involvement of novel coronavirus infection: prevention and control infection from a gastroenterology perspective. J Dig Dis 2020;(e-pub ahead of print). doi https://doi.org/10.1111/1751-2980.12862

8 Wong SC-Y, Kwong RT-S, Wu TC, et al. Risk of nosocomial transmission of coronavirus disease 2019: an experience in a general ward setting in Hong Kong. J Hosp Infect 2020;(e-pub ahead of print). doi https://doi.org/10.1016/j.jhin.2020.03.036

9 Li Q, Guan X, Wu P, et al. Early transmission dynamics in Wuhan, China, of Novel Coronavirus-Infected Pneumonia. N Engl J Med 2020;382(13):1199-1207

10 Marchese M, Capannolo A, Lombardi L, Di Carlo M, Marinangeli F, Fusco P. Use of a modified ventilation mask to avoid aerosolizing spread of droplets for short endoscopic procedures during coronavirus covid-19 outbreak. Gastrointest Endosc 2020;(e-pub ahead of print). doi https://doi.org/10.1016/j. gie.2020.03.3853

11 Lei Z, Cao H, Jie Y, et al. A cross-sectional comparison of epidemiological and clinical features of patients with coronavirus disease (COVID-19) in Wuhan and outside Wuhan, China. Travel Med Infect Dis 2020;(April) :101664

12 van Doremalen N, Bushmaker T, Morris DH, et al. Aerosol and surface stability of SARS-CoV-2 as compared with SARSCoV-1. N Engl J Med 2020;382(16):1564-1567

13 Tran K, Cimon K, Severn M, Pessoa-Silva CL, Conly J. Aerosol generating procedures and risk of transmission of acute respiratory infections to healthcare workers: a systematic review. PLoS One 2012;7(4):e35797

14 Bin SY, Heo JY, Song M-S, et al. Environmental contamination and viral shedding in MERS patients during MERS-CoV outbreak in South Korea. Clin Infect Dis 2016;62(6):755-760

15 Zou L, Ruan F, Huang M, et al. SARS-CoV-2 viral load in upper respiratory specimens of infected patients. N Engl J Med 2020;382(12):1177-1179

16 Bai Y, Yao L, Wei T, et al. Presumed asymptomatic carrier transmission of COVID-19. JAMA 2020;(e-pub ahead of print). doi:10.1001/jama.2020.2565

17 Xiao F, Tang M, Zheng X, Liu Y, Li X, Shan H. Evidence for gastrointestinal infection of SARS-CoV-2. Gastroenterology 2020;(e-pub ahead of print). doi https://doi.org/10.1053/j. gastro.2020.02.055

18 Xu J, Li Y, Gan F, Du Y, Yao Y. Salivary glands: potential reservoirs for COVID-19 asymptomatic infection. J Dent Res 2020;(e-pub ahead of print). doi 10.1177/0022034520918518

19 Eldin C, Lagier J-C, Mailhe M, Gautret P. Probable aircraft transmission of COVID-19 in-flight from the Central African Republic to France. Travel Med Infect Dis 2020;(April):101643 
20 Soetikno R, Teoh AY, Kaltenbach T, et al. Considerations in performing endoscopy during the COVID-19 pandemic. Gastrointest Endosc 2020;(e-pub ahead of print). doi https:// doi.org/10.1016/j.gie.2020.03.3758

21 Perisetti A, Gajendran M, Boregowda U, et al. COVID-19 and gastrointestinal endoscopies: current insights and emergent strategies. Dig Endosc Off J Jpn Gastroenterol Endosc Soc 2020

22 Mohandas KM, Gopalakrishnan G. Mucocutaneous exposure to body fluids during digestive endoscopy: the need for universal precautions. Indian J Gastroenterol 1999;18(3):109-111

23 Johnston ER, Habib-Bein N, Dueker JM, et al. Risk of bacterial exposure to the endoscopist's face during endoscopy. Gastrointest Endosc 2019;89(4):818-824

24 Chiu PWY, Ng SC, Inoue H, et al. Practice of endoscopy during COVID-19 pandemic: position statements of the Asian Pacific Society for Digestive Endoscopy (APSDE-COVID statements) Gut 2020;gutjnl-2020-321185
25 Group BMJP. Hot air? BMJ 2001;323:1449

26 Calderwood AH, Day LW, Muthusamy VR, et al; ASGE Quality Assurance in Endoscopy Committee. ASGE guideline for infection control during GI endoscopy. Gastrointest Endosc 2018;87(5):1167-1179

27 Beilenhoff $\mathrm{U}$, Biering $\mathrm{H}$, Blum R, et al. Reprocessing of flexible endoscopes and endoscopic accessories used in gastrointestinal endoscopy: Position Statement of the European Society of Gastrointestinal Endoscopy (ESGE) and European Society of Gastroenterology Nurses and Associates (ESGENA) - Update 2018. Endoscopy 2018;50(12):1205-1234

28 Repici A, Aragona G, Cengia G, et al. ITALIAN GI-COVID19 Working Group. Low risk of covid-19 transmission in GI endoscopy. Gut. 2020 Apr 22. pii:gutjnl-2020-321341. doi:10.1136/ gutjnl-2020-321341. [Epub ahead of print] 